\title{
Student Perceptions of Justification in Two Disparate Domains: Education and Biology
}

\author{
Christi L. Dawson ${ }^{1}$, Maeghan N. Hennessey ${ }^{1} \&$ Kelli Higley ${ }^{2}$ \\ ${ }^{1}$ Jeannine Rainbolt College of Education, The University of Oklahoma, Norman, Oklahoma \\ ${ }^{2}$ College of Education, The Pennsylvania State University, University Park, Pennsylvania \\ Correspondence: Maeghan N. Hennessey, Jeannine Rainbolt College of Education, The University of Oklahoma, 820 \\ Van Vleet Oval, Room 310, Norman, OK 73019, United States. Tel: 1-405-325-3574. \\ Received: March 31, 2016 \\ Accepted: April 25, 2016 \\ Online Published: April 28, 2016 \\ doi:10.5430/ijhe.v5n3p1 \\ URL: http://dx.doi.org/10.5430/ijhe.v5n3p1
}

\begin{abstract}
This study investigated the perceptions of epistemic justification of students in two disparate domains of study to determine if any similarities and differences in their methods of justification exist. Two samples of students, or a total of 513 undergraduates from educational psychology $(n=193)$ and biology $(n=320)$ courses, completed a domain-general instrument that measured student views of pedagogical practices designed to enhance epistemic justification. A 3-factor solution best fit the data for both samples, but there were similarities and differences in the factors identified for the two samples. Students in both samples conceptualized the importance of collecting data or observable evidence to aid in making links between concepts as well as recognized the importance of both internal and external justification practices. One important distinction between the two samples is that those in the education sample distinguished between verifying core concepts and verifying connections using observable evidence, but the biology sample did not. Results suggest there are differences between the methods of justification conceptualized by students from the two different domains. Suggestions for future research are forwarded.
\end{abstract}

Keywords: Epistemic Cognition, Justification, Epistemology, Domain-Specific Beliefs

\section{Introduction}

Much of what teachers do in classrooms is interpreted through students' epistemic worldviews (Hofer, 2004). These worldviews, in the form of beliefs, have been investigated by a number of different researchers (e.g., Hofer, 2000; Jehng, Johnson, \& Anderson, 1993; Schommer, 1990). Yet, students can hold beliefs about a myriad of different activities or occurrences in the classroom. What should be thoroughly investigated are the conceptions students hold about the pedagogical practices employed by their teachers used to instruct them in determining the viability of knowledge claims.

Justification of knowledge claims is an area that has recently begun to be studied in depth in the educational psychology literature. Although philosophers have been logically theorizing about the paths in which one arrives at truth as far back as the times of Plato and Aristotle (Murphy, 2003), those in educational psychology have only recently begun to study how individuals conceptualize justification (King \& Kitchener, 1994; Kuhn, 1991) and use different modes of justification in their own understandings of knowledge (e.g., Hofer, 2000).

\subsection{Development of the Field of Epistemic Cognition}

Beginning with the work of Perry (1970), psychologists began to investigate individuals' beliefs and connect them with their learning. It was not until King and Kitchener (1994) developed a framework of epistemic beliefs, though, that different methods of justification were explicitly investigated by researchers. Since that time, many researchers have conceptualized the justification processes by which students come to hold new knowledge in a myriad of different ways. For example, King and Kitchener (1994) stated that individuals holding different beliefs and having different levels of sophistication justified their beliefs by using a range of methods; for example, their perceptual experiences or their reasoning capabilities. This finding was echoed by Kuhn (1991). Hofer (2000) found that individuals conceptualized justification in two ways: by methods based on personal experiences or sources of authority outside the knower. 
Early in the investigation of personal epistemology, researchers investigated the extent to which individuals held epistemic beliefs without reference to content areas. These researchers investigated general beliefs in both unidimensional (e.g., Baxter Magolda, 1992; Kuhn, 1991; Perry, 1970) and multidimensional (e.g., Schommer, 1990, 1993; Schraw, Bendixen \& Dunkle, 2002) ways. These researchers did not explicitly state that beliefs were connected to the content in which the beliefs were held, but many of the researchers investigated relations among beliefs and content area achievement. Still, the beliefs held were considered to be domain-general because it was theorized that individuals would hold similar beliefs in a variety of different domains.

Much of the more recent research into epistemic cognition in general and justification in particular builds upon the multidimensional conceptions pioneered by Schommer (e.g., 1990, 1993), but extends this line of research to also investigate the extent to which beliefs are related to the content in which they are held. Specifically, researchers who were interested in the extent to which beliefs are held in domain-specific ways argue that there are differences in the domains themselves; thus, there must be differences in individuals' beliefs about those domains (Buehl, Alexander, \& Murphy, 2002; Hofer, 2000; Paulsen \& Wells, 1998). Other researchers have investigated the extent to which epistemic beliefs are held in topic-specific ways (e.g., Bråten, Strømsø, \& Samuelston, 2008; Palmer \& Marra, 2004), further fine-tuning this field of study. Still other researchers have surmised that both subject-specific and general epistemic beliefs are at play (e.g., Salovaara, 2005).

\subsection{Importance of the Domain of Study in Epistemic Cognition}

Much of the previous work done to investigate domain-specific epistemic cognitions contrasted the responses of individuals when asked questions about two or more different domains. However, interest and expertise in a domain may play a role in the responses a person offers and can predict things such as achievement (e.g., Bråten \& Strøms $\varnothing$, 2005; Cano, 2005; Rukavina \& Daneman, 1996; Schommer, 1993), approaches to learning (Cano, 2005), and knowledge integration (Rukavina \& Daneman, 1996). When participants respond to areas in which they had a particular interest or specialization, they exhibit more sophisticated epistemic cognitions. Participants who specialized in a particular subject or area had more sophisticated or higher levels of epistemic cognitions than participants who were not familiar with a particular subject. For example, Owen (2011) found graduate students in clinical or counseling psychology programs exhibited domain-specific epistemic cognitions that were elevated over their undergraduate counterparts and Nielson (2010) obtained similar results in an investigation with advanced music students enrolled in conservatories or academies. This refining of epistemic cognitions was found to parallel student development in learning the content in high school physics classrooms (Ogan-Bekiroglu \& Sengul-Turgut, 2011). It seems, then, that asking individuals to respond about only those areas in which they hold particular expertise may give a new insight into the acquisition of justification skills.

Development of learning in an area is not the only thing that contributes to the justification of knowledge claims. Domains have different characteristics and the extent is unknown as to which characteristics of the domains will influence the conditions under which one considers themselves to be justified in making a knowledge claim. For example, Palmer and Marra (2004) classified courses into social sciences/humanities areas and science/engineering areas to investigate belief change over time. They found that students enrolled in science/engineering courses exhibited more epistemic change and reasoned this was because the numerous courses they were required to take aided them in developing rich and deep understandings of the content about which they were asked. It appears, then, that the organization of the learning experiences within a student's domain of expertise can play a role in the development of their epistemic cognitions. It is important, then, to collect data on how students feel they should learn about justification from those who are developing expertise in disparate areas.

\subsection{Epistemic Beliefs: Philosophical Perspectives}

Justification of knowledge, or the set of conditions under which a person can state that they hold knowledge (Pollock \& Cruz, 1999), consists of the ways individuals gather and use evidence to help them evaluate claims (Conley, Pintrich, Vekiri, \& Harrison, 2004). Hofer and Pintrich (1997) stated that the types of justification individuals can use to evaluate claims can consist of evidence, opinions, authority figures, and the evaluation of the ideas of others (see also Chan \& Elliott, 2004; King \& Kitchener, 1994). Evidence used to provide justification for knowledge can also consist of individual opinions or the first-hand experiences of the knower (Hofer, 2000). In other words, these types of beliefs about justification can come from sources that are external to the knower or generated within the knower's mind (Kuhn, Cheney, \& Weinstock, 2000).

Although justification is central to acquiring knowledge, particularly in science (Conley et al., 2004), and individuals' epistemic beliefs have been shown to be related to a number of important educational outcomes, it is unknown the different types of justification conditions to which students adhere. These justification conditions have been studied 
briefly in the personal epistemology literature (e.g., Hofer, 2000; Kuhn, Cheney, \& Weinstock, 2000; King \& Kitchener, 1994), but their theoretical underpinnings have been developed in the philosophical literature. Specifically, philosophers have been interested in the conditions under which one can sufficiently state they are justified in holding a true belief, with different philosophers proposing varying methods as to how individuals provide justification for their beliefs. The strategies for teaching justification skills inherent in three of these frameworks (i.e., foundationalism, coherentism, and reliabilism) will be investigated in this study because they are directly applicable to conceptual change (Murphy, Alexander, Greene, \& Hennessey, 2012) and, thus, to the field of higher education. The categories of strategies teachers may use in the classrooms, or epistemic practices, are representative of the range of epistemic strategies individuals might employ in the pursuit of knowledge in their area (Richter \& Schmid, 2010; Vargas, 2012).

\subsubsection{Foundationalism}

Philosophers began the study of epistemology by establishing a framework for providing justification of beliefs known as foundationalism. For foundationalists, knowledge consists of a hierarchical arrangement of beliefs (Moser, 1995), where beliefs are either basic or non-basic. Under this justification framework, basic beliefs are defined as non-inferential and self-evident (Murphy et al., 2012) because they do not involve other beliefs in the establishment of justification. In other words, the person holding a basic belief does not make any inferences to "know" the basic belief (Fumerton, 2000). Second, basic beliefs are infallible, indubitable, and incorrigible, meaning they cannot be false, doubted, or corrected by others (Fumerton, 2000; Moser, 1995). The reason for these conditions is because basic beliefs exist only about individuals' perceptions of the object under question but are not properties of the object itself.

Under the framework of foundationalism, non-basic beliefs receive justification from basic beliefs by establishing a connection, or a line of justification, back to the original, basic beliefs (Kvanvig, 1986) using methods that can be either internal or external to the knower. The establishment of a line of justification back to the original, basic belief provides the condition under which a person can state they are justified in believing the new belief. Thus, "[a]ccording to foundationalism, all justification is ultimately traceable to the foundations of justification. Thus, all justified beliefs form a structure for there simply cannot be any justified beliefs not linked to the foundations" (Kvanvig, 1986 p.346).

\subsubsection{Coherentism}

Coherentists, on the other hand, suggest that knowledge gained is not hierarchically organized (Moser, 1995). Rather, the coherentist view is that all beliefs require justification (Kvanvig, 1986; Olsson, 2012) and are justified identically within the system (Olsson, 2012). In other words, coherentists emphasize that the hierarchical structure of basic and non-basic beliefs proposed by foundationalists does not exist.

For coherentists, justification relies exclusively on the establishment of a network of beliefs (Shogenji, 2001, 2007). In other words, the connection between beliefs generates justification for all beliefs within the system, and that justification may be generated by observations or perceptual experiences that are either internal or external to the knower. The larger the network of beliefs and more connections within that network, the greater the justification for all the beliefs existing within the system (Shogenji, 2007).

\subsubsection{Reliabilism}

In contrast, those who adhere to an epistemic orientation of reliabilism state that perceptual experiences of the knower are not a necessary condition for the establishment of justification. Rather, beliefs are only justified when produced through a reliable cognitive process or a history of reliable cognitive processes (Goldman, 1994). According to reliabilists, data gathered from either the internal belief system or external to the knower should be compared with hypotheses proposed by the individual knower. If the data supports the hypothesis, a reliabilist would claim that the individual has provided justification for their belief (Bach, 1985). It is important to note that, although the method for establishing justification in a reliabilist framework is different from the processes used by foundationalists and coherentists, none of the frameworks should be considered as superior. All types of justification strategies here are useful in varying contexts and with varying domains.

\subsection{Research Purpose}

Whatever types of evidence students use to provide justification for their beliefs, educators want to help them move through stages (King \& Kitchener, 1994) so that they can begin to develop reasoned justification for their beliefs (Chan \& Elliott, 2004). The goal of instructing students in methods of justification is to help them move away from holding naïve beliefs that are unevaluated or unjustified (King \& Kitchener, 1994) to those where individuals use evidence to show that preconceived notions are correct (MaClellan \& Soden, 2004). Focusing on student conceptions of their 
teachers' practices through this lens allows us to better inform our teaching by helping students to determine their preferred methods of evaluating knowledge (e.g., Bereiter, 2002; MaClellan \& Soden, 2004) so they can manage their own learning (Bernold, 2007).

In this paper, we will investigate epistemic justification strategies as they are understood by undergraduates enrolled in educational psychology and biology classes. Specifically, we are interested in the extent to which undergraduates enrolled in these two disparate types of coursework conceptualize epistemic beliefs in similar or different ways using a domain-general measure of epistemic beliefs assessing justification methods related to foundationalism, coherentism, and reliabilism.

\section{Method}

\subsection{Participants}

Participants for this study were 513 undergraduate students at a large northeastern research university in the U.S. enrolled in educational psychology $(n=193)$ and biology $(n=320)$ courses. Four hundred five $(79 \%)$ students were female. The majority of participants were Caucasian $(n=457,89 \%)$. The other ethnicities reported include African American, Asian American, Hispanic, or foreign, and each represented approximately 1-4\% of the participants. A little more than half of the participants were sophomores $(n=306,60 \%)$, with the rest of the students split across the freshmen, juniors, and seniors.

Education students were recruited from an introductory educational psychology course required for education majors and normally taken during the sophomore year. Among 193 educational psychology class students, one hundred fifty nine $(82 \%)$ students were female. The majority of participants were Caucasian $(n=180,93 \%)$. Approximately $86 \%$ of the participants were sophomores $(n=167)$, with the rest of the students split across the freshmen (2\%), junior (9\%), and senior (3\%) levels. Most students reported majoring in elementary education, secondary education, or communication sciences and disorders.

Biology students were recruited from two courses, one in human anatomy and one in physiology (including the laboratory course accompanying the physiology course). Among 320 biology class students, two hundred forty six $(77 \%)$ students were female. The majority of participants were Caucasian $(\mathrm{n}=277,87 \%)$. Approximately $44 \%$ of the participants were sophomores $(\mathrm{n}=139)$, with the rest of the students split across the freshmen (18\%), junior (23\%), and senior (15\%) class levels. Most students reported majoring in kinesiology, nursing, biobehavioral health, or bioengineering. Analyses were conducted separately for the two groups because there may be differences in their patterns of epistemic justification (Buehl \& Alexander, 2001) due to the differences in their expertise and domains of study (e.g., Palmer \& Marra, 2004; Richter \& Schmid, 2010).

\subsection{Instrument}

The instrument used in this study consisted of a modified version of the Likert-type items used to assess teacher epistemic beliefs developed and validated by Hennessey, Murphy, and Kulikowich (2013). This instrument was originally designed to measure whether or not teachers held to the justification frameworks of foundationalism, coherentism, and/or reliabilism as evidenced through their pedagogical practices. Hennessey and colleagues (2013) previously found this instrument to exhibit acceptable levels of reliability $(\alpha=0.88)$ across all items and for items assessing each justification framework (i.e., foundationalist: $\alpha=.70$; coherentist: $\alpha=.81$; reliabilist: $\alpha=.83$ ). For the current study, we were interested in assessing the beliefs of both teacher candidates and those not enrolled in education courses, so the instrument was modified to remove all references to teacher pedagogical practices from the items. For the purposes of this study, the questions were changed to reflect student views of pedagogical practices rather than what the teacher does in the classroom. However, the content of the questions was unchanged. For example, one item assessing a foundationalist justification strategy in the original instrument, "I teach my students understandings that are evident to everyone," was modified to read, "Understandings should be evident to everyone." An example of an item assessing a coherentist framework by Hennessey et al. (2013), "The examples I use in my teaching emphasize the ways in which concepts are related," was changed to read, "Examples should emphasize the ways in which concepts are related," for the current study. Finally, an example of an item assessing a reliabilist framework by Hennessey and colleagues (2013) was, "I teach my students to explain how their conclusions should be checked by using observable evidence." This item was modified to read, "Conclusions should be checked by using observable evidence," for use with students in the current study. Thirty Likert-type items were given to participants, with ten items assessing beliefs about each of the three types of justification strategies outlined above. Participants were asked to indicate their agreement with each item on a scale ranging from one to five, with one meaning strongly disagree and five meaning strongly agree. 


\subsection{Procedure}

Participants in both the educational psychology and biology courses were recruited for participation by the third author. The third author visited the educational psychology and human anatomy and physiology classes to inform individuals of the opportunity to participate in the research. Students being recruited from biology laboratory courses were sent emails to request their participation due to the large number of biology labs. Participants came to previously scheduled research sessions to respond to the instrument as part of a larger group of instruments.

\section{Results}

\subsection{Exploratory Factor Analyses}

Since much research has been completed about the domain- or topic-specific nature of epistemic beliefs (e.g., Bråten \& Strømsø, 2005; Buehl et al., 2002; Hofer, 2000; Nielson, 2010) and also the extent to which the structure of the domains under question may play a role in belief change in that area (e.g., Palmer \& Marra, 2004), we felt it was important to conduct exploratory factor analyses separately on the two sets of data to ascertain the nature of the pattern of responses exhibited by the educational psychology and biology students regarding the justification methods they feel are beneficial in classrooms. Data were submitted to exploratory analyses using SAS PROC FACTOR. We employed maximum likelihood estimation techniques and analyzed both the Akaike Information Criterion (AIC; Akaike, 1974) and Bayesian Information Criterion (BIC; Schwartz, 1978) to determine the number of underlying factors that best describe the patterns in the data. An examination of the change in the AIC and BIC values, where a small change in the values indicates the level at which the number of factors best explains the data structure, suggested that 3 -factor solutions best fit the data for both samples. We chose to allow the factors to correlate using Promax rotation in these analyses because the justification methods employed are not mutually exclusive. The exploratory factor analyses for each of the two samples will be described separately below.

\subsubsection{Education Sample}

The results of the EFA-ML for data collected from participants enrolled in educational psychology courses suggested that a 3-factor solution best described the structure of the data. Specifically, 14 items loaded at .30 or greater on Factor 1, nine loaded on Factor 2, and seven loaded on Factor 3. Of these items, three cross-loaded onto more than one factor and were eliminated from the analysis for ease in factor interpretation. Additionally, two items did not load highly on any of the three factors and were also removed from the analyses. Table 1 gives the rotated pattern matrix for this data. Factors 1 and 2 were correlated at .40, Factors 1 and 3 were correlated at .41 , and Factors 2 and 3 were correlated at .42 .

Table 1. Coefficients for the Exploratory Factor Analysis using Promax Rotation

\begin{tabular}{|c|c|c|c|c|c|c|}
\hline \multirow[b]{2}{*}{ Item } & \multicolumn{3}{|c|}{ Education Sample } & \multicolumn{3}{|c|}{$\begin{array}{l}\text { Biology } \\
\text { Sample }\end{array}$} \\
\hline & F1 & $\mathrm{F} 2$ & F3 & F1 & F2 & F3 \\
\hline $\begin{array}{l}\text { New understanding should be verified through the } \\
\text { collection of data. }\end{array}$ & .59 & .10 & .04 & .34 & -.18 & .25 \\
\hline $\begin{array}{l}\text { Links between as many concepts as possible } \\
\text { should be emphasized. }\end{array}$ & .58 & -.09 & -.06 & .63 & -.03 & -.12 \\
\hline $\begin{array}{l}\text { Concepts should be connected with other } \\
\text { previously learned concepts. }\end{array}$ & .54 & -.20 & .19 & .59 & -.09 & .02 \\
\hline $\begin{array}{l}\text { Newly learned information should build upon what } \\
\text { is known to be true. }\end{array}$ & .50 & .02 & .26 & .38 & .18 & .09 \\
\hline $\begin{array}{l}\text { Demonstrations show how reasoning can be } \\
\text { confirmed with data collected as evidence. }\end{array}$ & .46 & -.01 & .02 & .43 & -.03 & .03 \\
\hline $\begin{array}{l}\text { Premises underlying a topic should be central to } \\
\text { acquiring knowledge. }\end{array}$ & .42 & .29 & .05 & .56 & .10 & -.03 \\
\hline Links among concepts should be examined. & .42 & .21 & -.04 & .59 & -.12 & .06 \\
\hline $\begin{array}{l}\text { Examples should be supported by evidence } \\
\text { collected from the natural environment. }\end{array}$ & .42 & .04 & -.03 & .30 & -.18 & .21 \\
\hline
\end{tabular}


The content taught in school should show that many concepts are related.

Observations should be collected and described in order to inform understanding.

Examples should emphasize the ways in which concepts are related.

Explanations should show that new information is related to numerous concepts.

The content taught in school requires reasoning to be based on evidence.

Understanding should be justified with observable evidence.

Conclusions should be checked by using observable evidence.

New facts should be explained using facts known to everyone.

Thinking should be aligned with observable evidence.

Evidence should be provided for one's thinking.

Subject matter in school should be based on a few core concepts.

Observations should be based on facts that are always true.

Explanations based on observable evidence should be more viable than explanations not based on observable evidence.

New understanding should be explained as being consistent with one's existing knowledge base.

New information should align with what is already understood.

Demonstrations should reinforce basic understanding about a subject.

Most examples should be derived from a few basic understandings.

New facts should be explained by connecting them with existing understanding.

New facts should be explained by building upon basic understandings.

Facts should be based on known truths rather than opinion.

Understandings should be evident to everyone.

No one understanding is more important than any other.

\begin{tabular}{|c|c|c|c|c|c|}
\hline .42 & .22 & -.02 & .61 & .05 & -.09 \\
\hline .41 & .20 & -.02 & .25 & .03 & .31 \\
\hline .40 & .11 & .22 & .67 & .03 & .01 \\
\hline .36 & .17 & .21 & .34 & .13 & .07 \\
\hline .12 & .53 & -.04 & .11 & .13 & .24 \\
\hline .06 & .53 & .07 & -.03 & .15 & .60 \\
\hline .31 & .51 & -.17 & .04 & -.06 & .81 \\
\hline-.08 & .44 & .26 & -.03 & .55 & .10 \\
\hline .01 & .44 & .17 & -.05 & .29 & .32 \\
\hline .20 & .43 & .01 & .29 & .15 & .18 \\
\hline-.18 & .37 & .27 & -.12 & .64 & -.06 \\
\hline .07 & .36 & .11 & -.03 & .37 & .19 \\
\hline .24 & .33 & -.04 & -.08 & -.01 & .49 \\
\hline-.10 & .08 & .79 & .09 & .59 & .03 \\
\hline-.07 & .14 & .67 & -.09 & .54 & .04 \\
\hline .23 & .08 & .35 & .37 & .10 & .15 \\
\hline .03 & .07 & .31 & .19 & .41 & -.16 \\
\hline .31 & -.16 & .68 & .40 & .33 & .11 \\
\hline .30 & .02 & .50 & .33 & .36 & .03 \\
\hline .24 & .26 & -.03 & .21 & -.04 & .24 \\
\hline-.21 & .54 & .31 & -.08 & .61 & -.02 \\
\hline .10 & .02 & .12 & .02 & .03 & .11 \\
\hline
\end{tabular}

Note: Bold loadings indicate the item loads onto that factor.

Factor 1 consisted primarily of items written by Hennessey and colleagues (2013) and subsequently modified for this study reflecting participants' views that connecting and making links between concepts can be confirmed through the collection of data or observable evidence. For example, two items representative of those loading highly onto this 
factor were, "Links between as many concepts as possible should be emphasized," and, "New understanding should be verified through the collection of data." This factor was subsequently titled, Verifying Connections with Observable Evidence and appears to represent externalist methods of justification within both the reliabilist and coherentist frameworks described previously.

Some of the items loading onto Factor 2 were also originally designed to assess a reliabilist method of justification; that is, these items were written about the collection of observable evidence to confirm reasoning methods. However, the content of the reasoning in Factor 2 differed from that of Factor 1. Items assessing foundationalist conceptions of justification loaded highly on this factor with reliabilist items. An example of a foundationalist item loading onto this factor was, "New facts should be explained using facts known to everyone," and a reliabilist item loading onto this factor was, "Conclusions should be checked by using observable evidence." Overall, it appears that participants in the education sample responded that observations should also be made about core concepts, and these observations lead to the conclusion that the core concepts are known by everyone. This factor was titled, Verifying Core Concepts with Observable Evidence. The results indicate that this factor represents justification strategies that could be classified as using externalist methods about foundationalism.

Factor 3 consisted of only items originally designed to assess foundationalist and coherentist methods of justification, but all items loading onto this factor had one thing in common; that is, they assessed the importance justification being ascertained from the use of basic knowledge and information already understood by the knower. For example, two items loading onto this factor were, "Demonstrations should reinforce basic understanding about a subject," and, "New understanding should be explained as being consistent with one's existing knowledge base." These items all appeared to assess internalist conceptions of justification. Consequently, this factor was titled, Internal Justification using Basic Knowledge.

Reliability analyses showed acceptable levels of reliability for all factors and the total number of items retained in the assessment. Cronbach's alpha was found to be .87 for the 25 items loading highly onto only one of the three factors. For the 12 items loading onto Factor 1, alpha was .83. Alpha was .76 for the nine items loading onto Factor 2 and .62 for the four items loading onto Factor 3.

\subsubsection{Biology Sample}

Data collected from participants enrolled in biology courses exhibited a somewhat different factor structure. As with the education sample, the results of the EFA-ML for data collected from biology participants suggested a 3-factor solution best described the structure of the data, but the number and content of the items loading onto these three factors was different. Specifically, 14 items loaded at .30 or greater on Factor 1, eight loaded on Factor 2, and five loaded on Factor 3. Of these items, two loaded highly on more than one factor and were dropped from analysis to enable cleaner factor interpretation. Additionally, four items did not load highly on any of the three factors and were dropped from analysis. Table 1 gives the rotated pattern matrix for this data. Factors 1 and 2 were correlated at .47, Factors 1 and 3 were correlated at .39, and Factors 2 and 3 were correlated at 34 .

As with Factor 1 for students in the education sample, the majority of the items loading highly on Factor 1 for students in the biology sample also highly loaded onto Factor 1 in the education sample. Thus, this factor was also titled Verifying Connections with Observable Evidence in the biology sample.

Items loading highly on Factor 2 in the biology sample were similar to those loading highly on Factor 3 in the education sample. What is different about items loading onto Factor 2 in the biology sample is that more items loaded onto this factor than they did in the education sample (see Table 1). Still, the interpretation of this factor is similar, and the factor was titled, Internal Justification using Basic Knowledge.

Items loading onto Factor 3 were substantially different in the biology sample than in the education sample. All items loading onto this factor assessed the use of observable evidence to provide justification for knowledge, and each item used the term, "observable" or one of its forms. However, the content about which these observations could be made was not restricted to being about connections or core concepts; rather, the items loading onto this factor reflected observations in general ways. An example of an item loading highly onto this factor was, "Conclusions should be checked by using observable evidence." In this factor, participants in the biology sample appeared to note the importance of collecting evidence external to the knower as a method of justification for new knowledge, regardless of the content of that new knowledge. As such, this factor refers primarily to externalist methods of justification and can be titled, External Justification using Observable Evidence. 
As with the education sample, the reliability of the 24 items loading onto only one of the factors in the biology sample was acceptable $(\alpha=.84)$. Cronbach's alpha for the 12 items loading onto Factor 1 was $.80, .73$ for the seven items loading onto Factor 2, and .68 for the five items loading onto Factor 3.

\section{Limitations and Future Research}

As with all studies, some limitations with the current investigation can be identified that necessitate future research into the differences between justification conditions utilized by those studying different domains. First, the characteristics of the sample likely played a role in the specific results attained. Although the demographic characteristics of the individuals in the study mirrored the population of students in the classes from where they were recruited, they were predominately female and Caucasian. More research with male students and those of different races or ethnicities is warranted.

Similarly, the developmental levels of the students could have played a role in the justification factors identified here. The majority of students in this study were classified as sophomores. It would be interesting to compare the factor structure from this sample with those obtained from samples of students who were in upper levels of their undergraduate degrees, and also those who have achieved expertise in their fields. Further, this study was limited to the investigation of the justification strategies used by students in education and biology courses; other ill-structured and well-structured domains should be investigated to obtain an expanded sense of how diverse justification methods are used. Future research should also investigate the extent to which the differences in these justification conditions are reflective of domain differences or if differences in individual justification preferences lead them to gravitate toward domains using justification in the ways they prefer.

\section{Educational Significance}

Despite the need for future research, this study is an important step in determining the extent to which individuals in different fields conceptualize justification. Since students from different domain-specific areas conceptualize justification differently, teachers need to be aware of those conceptualizations. The results found in this study were unexpected as we thought students from two different domains would show markedly different methods of justification of knowledge. Recent studies have shown there are considerable differences between students in different domains and how they conceptualize methods of justification (Owen, 2011; Palmer \& Marra, 2004), however, those results were not as clearly evident in the biology and education samples in this study. These two diverse samples showed much more similarity than expected, leading us to suggest that future research is necessary to investigate the conditions under which individuals in different domains provide justification for their knowledge.

\section{Discussion and Implications}

The purpose of this paper was to investigate the justification conditions undergraduates enrolled in biology and educational psychology courses expect to use in their coursework. More specifically we looked at two entirely different subject domains to determine if students from each of these domains conceptualize these justification strategies in a similar or different manner by using a domain-general measure of epistemic justification. The results indicated a 3-factor solution was best for both samples of data, but the 3-factors solutions were not the same for both domains. In other words, both the biology and education samples of students were similar on their conceptualizations of two of the three factors but differed on the third factor.

The first factor, Verifying Connections with Observable Evidence had the same interpretations for both the education and biology samples. Specifically, this factor reflected participants' views about the importance of collecting data or observable evidence to aid in making links between concepts. The appearance of this factor suggests that it is likely the observation skills required of those in the science fields are the same as teacher candidates are taught to require of their students.

A second factor, entitled Internal Justification using Basic Knowledge appeared as Factor 3 in the education sample and Factor 2 in the biology sample. This factor supports Kvanig's (1986) definition of foundationalism as foundationalists can trace their justification back to the original, basic beliefs. The appearance of this factor in both samples suggests these undergraduate students perceive there is basic, foundational knowledge inherent to both domains.

The final factor in the two samples differed. In the education sample, a factor we entitled Verifying Core Concepts with Observable Evidence was found and represented the extent to which core concepts could be constructed or observed using data external to the knower. In the biology sample, the third factor was entitled External Justification using Observable Evidence. For the students of biology, all of the items from this factor measured the use of observable evidence to provide justification of knowledge, and all items used the term "observable," whereas the 
students enrolled in the educational psychology courses made a distinction between the use of observable evidence for the verification of core concepts and more general uses.

In summary, it seems that although both samples recognized that there are core concepts that are justified internally, there are other concepts that are justified externally. Students in the education sample distinguished between verifying core concepts and verifying connections using observable evidence but those in biology did not make the same distinctions. Instead, biology students distinguished the need to verify connections by using observable evidence, but did not distinguish any other categories of knowledge needing justification.

Biology students may focus solely on the need to verify connections by using observable evidence because in that specific domain, one must physically see the evidence to justify their knowledge. For example, it is easier to understand evolution when shown actual physical evidence, such as pictures, of a species adapting through time than it is to use core concepts to justify this knowledge. This goes back to the fact that certain beliefs are held in domain-specific ways because of the domain itself (Buehl, Alexander, \& Murphy, 2002; Hofer, 2000; Paulsen \& Wells, 1998). It makes sense that the biology domain would focus more on observable evidence rather than core concepts to justify knowledge. It would be a benefit for teachers to understand that the biology domain can be very complex and hard to understand, therefore, when possible, teachers should have their students verify connections using observable evidence such as pictures, diagrams, and microscopes.

It is possible students in the education sample distinguished between verifying core concepts and verifying connections using observable evidence based on the specific topic being conceptualized. In the education field, specifically educational psychology, topics being taught range from human learning theories to measurement and statistics. In determining the differences and similarities between human learning theories, students would probably verify core concepts to justify their knowledge. However, with measurement and statistics, students would verify connections using observable evidence by reviewing test items or statistics to justify their knowledge. Teachers need to be cognizant of the different ways students justify knowledge in order maximize student success of being able to verify core concepts or use observable evidence to justify their knowledge.

The results may also indicate that neither group exhibits highly sophisticated conditions under which they are able to say their knowledge is justified in their respective domains. Since the majority of students in both samples were sophomores, they may not yet hold a high level of knowledge about each domain. It is possible the distinction between the justifications of knowledge in the two domains would have been more prominent if participants gained more expertise in the area. Further research is needed to determine if students studying in the areas in the present study exhibit more sophisticated epistemic cognitions (e.g., Nielson, 2010; Owen, 2011).

In conclusion, although there are some limitations with this study, this research further asserts that there may be significant differences in justification of knowledge between different domains. For example, with a more hands-on domain such as biology, students verified connections using observable evidence over other conditions of justification. This may be because biology students need to physically see the evidence of what is being taught, such as the different parts of cell under a microscope or the diagrams of DNA in order to fully grasp the concepts. On the other hand, the diversity of topics inherent in educational psychology courses may have interacted with students' beliefs about how to justify knowledge in that domain. Results of this study show that higher education faculty must be cognizant of the nature of the domain and the justifications most appropriate in that domain when planning their instruction.

\section{References}

Akaike, H. (1974). A new look at the statistical model identification. IEEE Transactions on Automatic Control, 19(6), 716-723. http://dx.doi.org/10.1109/TAC.1974.1100705

Bach, K. A Rationale for reliabilism. http://userwww.sfsu.edu/ kbach/ratrel.htm

Baxter Magolda, M. B. (1992). Knowing and reasoning in college students: Gender-related patterns in students' intellectual development. San Francisco: Jossey Bass.

Bråten, I., \& Strømsø, H. I. (2005). The relationship between epistemological beliefs, implicit theories of intelligence, and self-regulated learning among Norwegian postsecondary students. British Journal of Educational Psychology, 75(4), 539-565. http://dx.doi.org/10.1348/000709905X25067

Bråten, I., Strømsø, H. I., \& Samuelstuen, M. S. (2008). Are sophisticated students always better? The role of topic-specific personal epistemology in the understanding of multiple expository texts. Contemporary Educational Psychology, 33(4), 814-840. http://dx.doi.org/10.1016/j.cedpsych.2008.02.001 
Bereiter, C. (2002). Education and mind in the knowledge age. Mahwah, NJ: Lawrence Erlbaum.

Bernold, L. E. (2007). Early warning system to identify poor time management habits. International Journal of Engineering Education, 23(6), 1182-1191.

Buehl, M. M., \& Alexander, P. A. (2001). Beliefs about academic knowledge. Educational Psychology Review, 13(4), 385-418. Doi: 10.1023/A:1011917914756

Buehl, M. M., Alexander, P. A., \& Murphy, P. K. (2002). Beliefs about schooled knowledge: Domain specific or domain general? Contemporary Educational Psychology, $27(3): \quad 415-449$. http://dx.doi.org/10.1006/ceps.2001.1103

Cano, F. (2005). Epistemological beliefs and approaches to learning: Their change through secondary school and their influence on academic performance. British Journal of Educational Psychology, 75(2), 203-221. http://dx.doi.org/10.1348/000709904X22683

Chan, K.-W., \& Elliott, R. G. (2004). Epistemological beliefs across cultures: Critique and analysis of beliefs structure studies. Educational Psychology, 24(2), 123-142. http://dx.doi.org/10.1080/0144341032000160100

Conley, A. M., Pintrich, P. R., Vekiri, I., \& Harrison, D. (2004). Changes in epistemological beliefs in elementary science students. Contemporary Educational Psychology, $29(2), \quad$ 186-204. http://dx.doi.org/10.1016/j.cedpsych.2004.01.004

Fumerton, R. Foundationalist theories of epistemic justification. http://plato.stanford.edu/entries/justep-foundational/

Goldman, A. I. (1994). Argumentation and social epistemology. The Journal of Philosophy, 91(1), 27-49. http://dx.doi.org/10.2307/2940949

Goldman, A. Social epistemology. http://plato.stanford.edu/entries/epistemology-social

Hennessey, M. N., Murphy, P. K., \& Kulikowich, J. M. (2013). Investigating teachers' beliefs about the utility of epistemic practices: A pilot study of a new assessment. Instructional Science, 41, 499-519. http://dx.doi.org/10.1007/s11251-012-9241-6

Hofer, B. K. (2000). Dimensionality and disciplinary differences in personal epistemology. Contemporary Educational Psychology, 25(4), 378-405. http://dx.doi.org/10.1006/ceps.1999.1026

Hofer, B. K. (2004). Epistemological understanding as a metacognitive process: Thinking aloud during online searching. Educational Psychologist, 39(1), 43-55. http://dx.doi.org/10.1207/s15326985ep3901_5

Hofer, B. K., \& Pintrich, P. R. (1997). The development of epistemological theories: Beliefs about knowledge and knowing and their relation to learning. Review of Educational Research, 67(1), 88-140. http://dx.doi.org/10.3102/00346543067001088

Jehng, J.-C. J., Johnson, S. D., \& Anderson, R. C. (1993). Schooling and students' epistemological beliefs about learning. Contemporary Educational Psychology, 18(1), 23-35. http://dx.doi.org/10.1006/ceps.1993.1004

King, P. M. \& Kitchener, K. S. (1994). Developing reflective judgment: Understanding and promoting intellectual growth and critical thinking in adolescents and adults. San Francisco: Jossey Bass.

Kuhn, D. (1991). Skills of argument. Cambridge, England: Cambridge University Press. http://dx.doi.org/10.1017/CBO9780511571350

Kuhn, D., Cheney, R., \& Weinstock, M. (2000). The development of epistemological understanding. Cognitive Development, 15(3), 309-328. http://dx.doi.org/10.1016/S0885-2014(00)00030-7

Kvanvig, J. L. (1986). The confusion over foundationalism. Philosophia, 16, 345-355. http://dx.doi.org/10.1007/BF02379752

MaClellan, E., \& Soden, R. (2004). The importance of epistemic cognition in student-centered learning. Instructional Science, 32(3), 253-268. http://dx.doi.org/10.1023/B:TRUC.0000024213.03972.ce

Moser, P. K. (1995). Epistemology. In R. Audi (Ed.), Cambridge dictionary of philosophy, (pp. 233-238). New York: Cambridge University Press.

Murphy, P. K. (2003). The philosophy in thee: Tracing philosophical influences in educational psychology. Educational Psychologist, 38(3), 137-145. http://dx.doi.org/10.1207/S15326985EP3803_3

Murphy, P. K., Alexander, P. A., Greene, J. A., \& Hennessey, M. N. (2012). Examining epistemic frames in conceptual change research: Implications for learning and instruction. Asia Pacific Education Review, 13, 
475-486. http://dx.doi.org/10.1007/s12564-011-9199-0

Nielsen, S. G. (2010). Epistemic beliefs and self-regulated learning in music students. Psychology of Music, 40(3), 324-338. http://dx.doi.org/10.1177/0305735610385509

Ogan-Bekiroglu, F., \& Sengul-Turgut, G. (2011). Students' general and physics epistemological beliefs: A twofold phenomenon. Research in Science and Technological Education, 29(3), 291-314. http://dx.doi.org/10.1080/02635143.2011.594790

Olsson, E. Coherentist theories of justification. http://plato.stanford.edu/entries/justep-coherence/

Owen, J. J. (2011). Domain specificity and generality of epistemic cognitions: Issues in assessment. Journal of College Student Development, 52(5), 622-630. http://dx.doi.org/10.1353/csd.2011.0061

Palmer, B., \& Marra, R. M. (2004). College student epistemological perspectives across knowledge domains: A proposed grounded theory. Higher http://dx.doi.org/10.1023/B:HIGH.0000016445.92289.f1

Paulsen, M. B., \& Wells, C. T. (1998). Domain differences in the epistemological beliefs of college students. Research in Higher Education, 39(4), 365-384. http://dx.doi.org/10.1023/A:1018785219220

Perry, W. G. (1970). Forms of intellectual and ethical development in the college years: A scheme. New York: Holt, Rinehart, \& Winston.

Pollock, J. L., \& Cruz, J. (1999). Contemporary theories of knowledge (Vol. 35). New York: Rowman \& Littlefield.

Richter, T., \& Schmid, S. (2010). Epistemological beliefs and epistemic strategies in self-regulated learning. Metacognition and Learning, 5(1), 47-65. http://dx.doi.org/10.1007/s11409-009-9038-4

Rukavina, I., \& Daneman, M. (1996). Integration and its effect on acquiring knowledge about competing scientific theories for text. Journal of Educational Psychology, 88(2), 272-287. http://dx.doi.org/10.1037/0022-0663.88.2.272

Salovaara, H. (2005). An exploration of students' strategy use in inquiry-based computer-supported collaborative learning. Journal of Computer Assisted Learning, 21(1), $39-52$. http://dx.doi.org/10.1111/j.1365-2729.2005.00112.x

Schommer, M. (1990). Effects of beliefs about the nature of knowledge on comprehension. Journal of Educational Psychology, 82(3), 498-504. http://dx.doi.org/10.1037/0022-0663.82.3.498

Schommer, M. (1993). Epistemological development and academic performance among secondary students. Journal of Educational Psychology, 85(3), 406-411. http://dx.doi.org/10.1037/0022-0663.85.3.406

Schraw, G., Bendixen, L. D., \& Dunkle, M. E. (2002). Development and validation of the Epistemic Belief Inventory (EBI). In B. K. Hofer \& P. R. Pintrich (Eds.), Personal epistemology (pp. 261-275). Mahwah, NJ: Lawrence Erlbaum Associates.

Shogenji, T. (2001). The role of coherence in epistemic justification. Australasian Journal of Philosophy. 79(1), 90-106. http://dx.doi.org/10.1080/713659180

Shogenji, T. (2007). Why does coherence appear truth-conducive? Synthese, 157(3), 361-372. http://dx.doi.org/10.1007/s11229-006-9062-8

Vargas, P. M. D. (2012). Toward a model of epistemic cognition: A mixed method study. (Doctoral dissertation). Retrieved from ProQuest. (AAT 3507733). 